\title{
Interprofessional Collaboration in the Care of Children With Complex Care Needs: The Experiences of Children, Their Families, and the Intersectoral Care Team
}

\author{
Jillian Lamb로 BSc; Shelley Doucet ${ }^{2,3}$, PhD, RN; and Alison Luke ${ }^{2,3}, \mathrm{PhD}$ \\ ${ }_{1}$ NaviCare/SoinsNavi, New Brunswick \\ 2 Department of Nursing \& Health Sciences, University of New Brunswick \\ ${ }^{3}$ Dalhousie Medicine New Brunswick
}

DOI: https://doi.org/10.15273/hpj.v1i2.10654

\begin{abstract}
Introduction: Coordinated care has the potential to provide positive outcomes for children with complex care needs (CCN) and their caregivers. This population requires a multitude of services that are administered by various providers across sectors. Research has shown that care for this demographic can be improved through interprofessional care models and communication among providers. The primary objective of this study was to explore the barriers to collaboration among members of the care team. The second objective was to identify ways to improve coordination between caregivers and providers. Methods: This qualitative study focused on the perspectives of caregivers of children with CCN, health professionals, educators, and social care providers regarding their experiences with interprofessional collaboration in the care of children with CCN and their families in two Atlantic Canadian provinces (New Brunswick and Prince Edward Island). The study was conducted using semi-structured interviews of 32 family members and 88 stakeholders from the educational, health, and social sectors. Interview data were analyzed using thematic analysis (Braun \& Clarke, 2006). Results: Participants included caregivers, health-care providers, educators, social workers, and therapists. All participants were involved in the care of children with CCN. Findings indicate that participants experience difficulties when accessing primary care and support services for children with CCN. These barriers were correlated with fragmented and uncoordinated care. Results were organized into three main themes: (a) Role Clarification, (b) Communication, and (c) Patient/Family-Centred Care. Each theme was explained through subthemes highlighting experiences of caregivers and care providers across sectors. Discussion: This study emphasized the need for increased research and evidence-based practices to address the current barriers to collaboration among care providers and caregivers when caring for children with CCN. By providing a patient-centred approach, there is opportunity to improve collaboration among providers and with caregivers while meeting the care needs of children with CCN.
\end{abstract}

Keywords: interprofessional, communication, disability, child, caregiver, care coordination, medical complexities 
Interprofessional Collaboration in the Care of Children with Complex Care Needs: The Experiences of Children, Their Families, and the Intersectoral Care Team

The worldwide incidence of children with complex care needs (CCN) under the age of 14 has increased over the last decade (Brenner et al., 2018; UNICEF, 2013; World Health Organization, 2011). In Canada, the number of children with complex health needs is reported to be $3.7 \%$ of the pediatric population (Statistics Canada, 2008). A child with CCN refers to multidimensional health and social care needs in the presence of a recognized medical condition or where there is no unifying diagnosis. They are individual and contextualized, are continuing and dynamic, and are present across a range of settings, impacted by healthcare structure (Brenner et al., 2018, p. 1647).

This population is defined as having complex disorders, multiple chronic conditions and/or genetic conditions. A few examples of these complexities are autism spectrum disorder, global developmental delay, brain and spinal cord malfunction, muscular dystrophies, heart malformations, cystic fibrosis, Down syndrome, and cerebral palsy. This population of children presents challenges when coordinating care due to their medical complexities (Cohen et al., 2011). This population requires a multi-faceted level of care from a wide range of providers across health, education, and social services (McPherson et al., 1998; World Health Organization, 2011).

As the prevalence of children with CCN increases, there is a demand to focus on improving the current health-care landscape for this population (Barnert et al., 2019; Looman et al., 2020; Shimmura \& Tadaka, 2018). Without access to services and providers, caregivers of children with CCN must resort to constant trips to the emergency room or large city centres with specialized professionals to receive the care their child needs. There has been increased attention paid to research focusing on children with CCN in the last decade (Barnert et al., 2019; Cohen et al., 2018). This focus has primarily aimed attention at the prevalence of this population, the program interventions that need to be put in place to best address their needs, and health care system costs (Cohen et al., 2018; Looman et al., 2020; Shimmura \& Tadaka, 2018). A majority of the studies focused on using a coordinated care approach in either hospital settings or primary-care models to support the care of children with CCN (Barnert et al., 2019; Boudreau et al., 2014; Cohen et al., 2018; Looman et al., 2020; Shimmura \& Tadaka, 2018). The studies that promoted the use of interprofessional care for children with CCN were conducted primarily within the United States. Study designs varied, but the majority were conducted using a scoping or systematic review of the literature or a cross-sectional study using questionnaires or observations, while one article analyzed the quantitative data from a national survey. The body of literature for this population is still small, and more research needs to be directed toward finding ways to improve care for children with CCN and their families (Barnert et al., 2019; Boudreau et al., 2014; Brenner et al., 2018; Cohen et al., 2018; Looman et al., 2020; Shimmura \& Tadaka, 2018).

The importance of delivering patientfocused care that addresses the needs of those requiring medical attention is widely recognized (Barnert et al., 2019; Boudreau et al., 2014; Cohen et al., 2018; Looman et al., 2020). As stated above, recent evidence emphasizes the lack of patient satisfaction across health-care settings, a concern that could be addressed through interprofessional collaboration among the intersectoral team (Barnert et al., 2019; Looman et al., 2020). Interprofessional collaborative practice focuses on highlighting the knowledge, skills, attitudes and values of care providers by integrating six competency domains: (a) interprofessional communication, (b) patient/client/family/community-centred care, (c) role clarification, (d) team functioning, (e) collaborative leadership, and (f) interprofessional conflict resolution (Canadian Interprofessional Health Collaborative, 2010). Through the integration of these six domains, health workers can work to facilitate a dynamic foundation for interprofessional learning and 
practice, improving health-care access and quality across sectors (Stewart, 2018). This study was part of a larger study exploring the needs of children with CCN and their families. After an analysis of the interviews from the larger study was completed, the findings indicated a clear need to improve communication among those providing care and support for children with CCN. The primary objective of this study was to explore the barriers to collaboration among members of the care team. The second objective was to identify ways to improve coordination between caregivers and providers.

\section{Purpose of the Study}

Children with CCN require a multitude of services that are arranged by various providers across sectors. Research has shown that care for this demographic can be improved through interprofessional care models and communication among providers. The purpose of this study was to explore the perspectives of caregivers, health professionals, educators, and social care providers regarding their experiences with interprofessional collaboration in the care of children with CCN and their families in two Atlantic Canadian provinces.

\section{Methods}

This research study is part of a larger mixed-methods project exploring the needs of children with CCN and their families. Further details on the research protocol are published in Doucet et al. (2017). Employing a qualitative descriptive design, this study examined the experiences of children, their families, and members of the care team with interprofessional collaboration in the care of children with CCN and their families. This study took place in two Canadian provinces: New Brunswick (NB) and Prince Edward Island (PE) in 2016. NB and PE are sparsely populated, with nearly half of the population located in rural areas. In addition, NB is a bilingual province with both English- and French-speaking residents. Letters were sent by mail, electronically and traditionally, to eligible participants. The 120 eligible participants were either interviewed individually $(\mathrm{n}=97)$ or attended a focus group $(n=23)$ and comprised the following: children with CCN ( $\mathrm{n}=5)$; family members of children with CCN $(n=32)$; health professionals $(n=40)$; education professionals $(\mathrm{n}=17)$; and social care professionals $(n=26)$. All interviews were conducted in person using an open-ended question format. The interviews were audiotaped and transcribed verbatim. For the purpose of this study, only the perspectives of caregivers of children with CCN and the care team were included. The interviews of children with CCN were thematically analyzed; however, the answers they provided to the questions were not relevant to the objective of the study. Their interviews have been used in the larger research study. The interviews used open-ended questions to allow the opportunity for participants to describe their experiences in a first-person narrative. The questions explored the needs of children with CCN and their families, the role of the care team, and the gaps and barriers in each province. Separate questions were asked to caregivers and the care team that related to their role in providing support to children with CCN. Ethics approval was obtained prior to recruitment and data collection and, following an explanation of the study, all participants provided informed consent. Ethics approval for this project was received from (a) University of New Brunswick-Saint John (\#023-2015), (b) Mount Alison University (\#2016-044), (c) University of Prince Edward Island (\#6006412), (d) Horizon Health Network in NB (\#20162329), and (e) the PEI Research Ethics Board (no file \#). Transcribed interviews were analyzed using Braun and Clarke's (2006) six phases of inductive thematic analysis. Following these guidelines, themes were developed and refined through a collaborative team approach among the authors.

\section{Results}

A range of concerns surrounding interprofessional care for children with CCN were identified through stakeholder and caregiver interviews. Key quotes from 
interviews were selected to reflect overarching themes from the study. Quotes from caregivers (C), health professionals (HP), and educators (E) were chosen to be included. The limitations to providing optimal care to children with CCN were recognized and organized into three themes: (a) role clarification, (b) communication, and (c) patient/family-centred care. Table 1 provides an overview of the main themes and subthemes.

\section{Role Clarification}

Participants noted that clear roles and responsibilities for each member of the care team will provide them with a clear definition of their position and indicate what gaps need to be addressed. This first theme includes two subthemes: (a) education and knowledge of care providers, and (b) team structure.

\section{Education and Knowledge of Care Providers}

Stakeholders found it challenging to focus on providing only their scope of practice for children with CCN. The limited number of care providers forces stakeholders to not only provide their scope of care, but also act as a source of support or have knowledge in areas outside of their expertise. One concern of caregivers was the lack of education stakeholders had when caring for children with CCN. Without this quality of knowledge and education, stakeholders are not delivering the highest quality of care to patients. One caregiver stated the need for stakeholders to be educated on the latest evidence-based research when providing care for children with CCN:

I would think no children with any amount of complexity would have much of anything done in Saint John anymore. There was a time when all of their G-tubes would have been done here and the trachs would have been done here and that kind of stuff under the name of a generalist. Not even just complex kids but simple surgical procedures, it's hit or miss whether it would be done here now depending on the comfort level of the person who is on call. (C)

Table 1

Themes and Subthemes

\begin{tabular}{|l|l|}
\hline Themes & Subthemes \\
\hline Role Clarification & a) Education and knowledge of care providers \\
& b) Team structure \\
\hline Communication & a) Interpersonal (between care providers) \\
& b) Technology (to facilitate the transfer of information \\
& c) Privacy (barriers communicating with providers across \\
\hline Patient/Family-Centred Care & a) Repeating their story \\
\hline
\end{tabular}




\section{Team Structure}

Lack of communication when navigating a provider's role in the care plan of the child was addressed in the interviews. A stakeholder spoke about the lack of structure and sharing of knowledge regarding a child's care plan:

Sometimes we find difficulty collaborating with schools for example. Some schools are more open to collaboration meetings, and some schools are totally not. They just don't want to meet. They refuse to meet, and they don't get us involved in meetings if they're meeting with families. Even knowing that we're involved in the care of the child, so this kind of collaboration really is necessary and we should try to break this silo of education and health system and social services. They, we really should collaborate more and we are not. (HP)

\section{Communication}

The second theme refers to effective communication. This can be defined as methods of relaying information, either verbally or in other forms, to those involved. If either party lacks a clear understanding of the information exchanged, the communication can be jeopardized. Communication is multi-faceted and includes three subthemes: (a) interpersonal, (b) technology, and (c) privacy.

\section{Interpersonal}

Communication among providers is still a current barrier that needs to be addressed to provide optimal patient care. One stakeholder commented on the communication barriers between providers:

I think communication and roots of communication tend to be the biggest barriers. Most fields work in their own niche and despite the overuse of the term, most sectors are silo-ed. I think without the proper channels to communicate, often we're not working together toward the best end and that certainly isn't good for anyone! (HP)
Another stakeholder also commented on the problems that currently occur when stakeholders are trying to collaborate on a patient's care:

Well, sometimes it's a barrier because there's multiple people involved in the care of a child. Trying to stay in touch with everybody and coordinate everybody can just be logistically a challenge. Sometimes people aren't always easy to reach. Sometimes you end up playing phone tag through the best of efforts with people to try and coordinate. (HP)

The barriers to communication among care providers within the health care system needs to be addressed.

\section{Technology}

A common problem among stakeholders was the lack of consistency when accessing information on individual patients. Referrals between stakeholders can get lost or delayed due to current inefficient methods of communication being utilized. One health-care worker described the complications that can occur when there is more than one type of health-care charting system being used:

There's different charting systems too, depending on where you're located. So, at the hospital, for example, we do paper charting for outpatients, but then for inpatients we use a system called Cerner. Whereas like, the speech therapist and dieticians and so on, use a system called ISM and those two systems are not compatible with each other. (HP)

\section{Privacy}

Stakeholders discussed some of the current issues surrounding confidentiality when communicating within the care team. This included the sharing of patient information among providers from different sectors (e.g., education, health, social services, government). One health-care provider expressed their apprehension surrounding privacy concerns: 
Some of it has to [do] with something simple, even like confidentiality, because every organization has different regulations around what they're allowed to share and what they're not allowed to share and at what age a child is considered adult. So, what we're allowed to share even around the table is not the same, unless they eliminate that barrier as well. (HP)

Privacy laws also restrict the information shared between stakeholders in different provinces. One stakeholder acknowledged the complications when dealing with cross-province care:

Services and sharing that information with outside of the province services and then getting information back from those outside of province services in a timely manner so we're able to help support families and their children to follow up on any of those recommendations and so sometimes there is good communication both ways and sometimes that doesn't work so, it's just not as timely and efficient as it could be. (E)

\section{Patient/Family-Centred Care}

The third theme reflects the need for a model of care that is more patient or family centred. Participants reported a need for an approach to care that is responsive and respectful of the patient's needs and requires a partnership between those receiving care and the care provider. This theme, patient/familycentred care, has two subthemes: (a) repeating their story and (b) involvement in care plan.

\section{Repeating Their Story}

Many caregivers felt frustrated when they constantly had to repeat their child's medical history and needs at every appointment. They expressed their desire to be included in the care plan but did not want to be relied upon as the sole source of information. One caregiver stated,
So, although they are really great because they know when I go in there that I have all this background and they really, I mean they listen to me as kind of the expert on that to help guide them. It would just be nice if they had more information, so it wasn't me. (C)

Another caregiver commented on how a coordinated care plan would help ensure they did not have to repeat their child's story numerous times:

Well the fact that all those services would be in one place, one location, would be a big thing in itself. I don't imagine it would be the family having to share their story over and over and over with many different doctors and many different service providers. They would share that once and that would be it and there to help you. I believe that, just the idea itself is a very positive thing and the outcomes are probably going to be very good. $(C)$

\section{Involvement in Care Plan}

Caregivers and family members also expressed their desire to be a part of the planning process for the child's care plan. Most caregivers felt they were not listened to, or did not have a say in the plan being provided. A stakeholder commented on the benefits of using a coordinated model of care:

Their distinct needs are that they need a coordinated team approach that will help them to understand everything that's going on with their child and all the different services that need to be involved. And, how all those are coordinated. So, I think, because, a lot of the families can be overwhelmed by just the illness and then all the different people that they may have to see. (HP)

Addressing ways to improve the caregiver's involvement in the child's plan is necessary. A caregiver commented on how to improve knowledge family-centred care: 
When you have interprofessional team members sitting on a team, then the knowledge, talent, that they do bring to the teams, and having that child and that family at the centre, and the recoverybased approach would follow the pathway of that child and making sure that we only provide the least restrictive measures and in trying to address the needs of that child. (C)

By collaborating, stakeholders would be able to work together and communicate effectively to optimize the way patients are currently being supported.

\section{Discussion}

This study sought to better understand the gaps to accessing coordinated care for children with CCN. This study identified the current knowledge gap among providers as well as the need to improve communication across disciplines to focus on a patient-centred care approach. Caring for children with CCN is challenging, as each child needs an individualized and dynamic plan involving a range of care providers (Brenner et al., 2018). Previous studies have demonstrated that caregivers of children with CCN experience distress and emotional burden as a result of inadequate support from professionals (Brehaut \& Kohen, 2016; Brenner et al., 2018; Carter et al., 2007).

The findings from this study highlight a demand to improve the current structure of coordinated care for children with CCN. Stakeholders in this study felt they needed more support in their role when providing care for complex patients. Having to handle their professional scope of practice, while simultaneously acting as a source of knowledge for their patients' other medical and social needs, became a challenge. Poorly defined roles can become a source of conflict and confusion in care settings (Baker \& Denis., 2011; Brault et al., 2014; Nelson et al., 2014).

Interview participants emphasized the lack of collaboration among care providers of children with CCN. Nuyen et al. (2019) addresses the importance of teams encompassing a range of interprofessional providers for improving the quality of care and outcomes for this population. Brenner et al. (2018) found that it is not possible for only one specialist or professional to possess all the knowledge needed to provide high quality care for children with CCN; care providers must work together when delivering quality patientcentred care. A coordinated care approach would provide an opportunity for providers to work together and educate one another on each child's comprehensive needs (Brenner et al., 2018; D'Amour et al., 2005; Nzirawa, 2015; Vos et al., 2020; Zwarenstein \& Reeves, 2006).

The complex needs of these children require professionals to collaborate, share knowledge, and work as a team. Implementing an interprofessional care approach would allow providers to communicate effectively regarding a patient's needs and how they can best care for their patient within their scope of practice (Brenner et al., 2018; D'Amour et al., 2005; Nelson et al., 2014; Zwarenstein \& Reeves, 2006). Clear communication between care providers will reduce time wasted in organizing an effective care plan for patients, as well as improve the relationship between stakeholders and families.

According to stakeholder participants, another barrier to accessing care is privacy conflicts among providers and provinces. There is often a lack of continuity of information sharing among providers, which has been found to result in a reduction in collaboration among providers and a lack of timely access to services for children with CCN. Interview participants also highlighted the inconsistencies encountered when trying to access patient information quickly. Technology can be used to improve the current challenges providers have when trying to communicate. Electronic health records and charting systems have been shown to support coordination and communication among health providers. Electronic health records in hospitals have led to a decrease in duration of time spent in the hospital, increased patient satisfaction with the care provided, and 
a decreased number of readmissions (Vos et al., 2020; Wani \& Malhotra, 2018). This demonstrates that the use of integrated care plans could improve both the care of children with CCN and the collaboration and sharing of information among providers (Brenner et al., 2018; Vos et al., 2020; Wani \& Malhotra, 2018).

Problems between providers directly affect the patients and their care needs. The need for providers to put the well-being of the patient first is crucial in developing effective plans for children with CCN. Participants discussed the stress that caregivers of children with CCN felt when constantly repeating their child's history and having to be a "walking" medical record. Caregivers in this study expressed that valuable time was wasted in appointments by having to reiterate information that could be provided to stakeholders before the time of an appointment (Brenner et al., 2018; Charlton et al., 2017; Samwell, 2012). Implementing medical record systems to facilitate easy and secure access to clients' medical history is one way to lessen the extra burden placed on caregivers (Vos et al., 2020; Wani \& Malhotra, 2018).

At present, there are both gaps in and barriers to the resources and services available for caregivers of children with CCN. Caregivers may encounter systemic barriers obstructing their knowledge of existing resources, an issue that health-care providers do not always have the knowledge or expertise to counter, and once that information is provided to families it can be challenging for them to gain access to the resources. Improving the communication between the intersectoral team members will allow providers to better educate families on the current resources for children with $\mathrm{CCN}$ and how to access them (Brenner et al., 2017; Brenner et al., 2018; Charlton et al., 2017). Ensuring the intersectoral team is using evidence-based practices was a concern raised by caregivers during the interviews. Having care providers keep up to date on the latest research and best practice methods would also improve the current care model used for children with CCN (Brenner et al., 2018; Cohen et al., 2018; Looman et al., 2020). Caregiver participants commented on their desire to be part of their child's care plan. Some felt they were never included in the planning and were not given the time they needed to understand and ask questions about their child's present and future care. Not allowing caregivers to be part of the planning of care could damage the trust of the provider-caregiver relationship. This mistrust can have a negative impact on the outcomes of the child (Baird et al., 2016; Brenner et al., 2018; Ward et al., 2015). The findings from this study reflect many of the six interprofessional competency domains outlined in the introduction. Incorporating interprofessional communication when providing care for patients allows the intersectoral team members to work together effectively. The results section discusses the many frustrations the intersectoral team has when providing care for children with CCN. Outlining clear responsibilities for each role allows providers to collaborate effectively and reduces conflicts that may arise between professionals. Providing patient/family-centred care ensures that patients' values and needs guide all decisions and strengthens the patient-provider relationship. Moving forward, it is important to find ways to integrate these competencies into practice to improve the care being provided to children with CCN and their caregivers.

\section{Limitations}

This study was a qualitative study that drew on participants' perspectives and concerns about collaboration and communication among health workers who support children with CCN and their caregivers. This study does have some limitations. First, our findings focused on the needs and perspectives of those in NB and PE populations and therefore may not be transferable to other populations. Second, an interview approach was used where sampling bias could have occurred, and it may not be an accurate representation of the entire population and their perspectives. However, this study provided a strong initial assessment of interprofessional collaboration when caring for children with CCN populations in two Atlantic 
Canadian provinces and is a starting point for future studies.

\section{Conclusion}

Findings from the study support the need to improve collaboration between providers and caregivers when caring for children with CCN. Reducing the current barriers to accessing information by utilizing consistent reporting systems, as well as improving the coordination of care through developing interprofessional collaboration practices, are a few ways to improve communication among the groups involved in this study. Providers need to focus on addressing patient and caregiver concerns to improve patient/family-centred care moving forward. Caregivers want to be included in the care plan of their child and have their concerns listened to. Implementing communication strategies to reduce the number of times a caregiver has to repeat their child's medical history will improve the provider-caregiver relationship. These key findings need to be considered when informing current and future policy improvements.

\section{References}

Baird, J., Rehm, R. S., Hinds, P. S., Baggott, C., \& Davies, B. (2016). Do you know my child? Continuity of nursing care in the pediatric intensive care unit. Nursing Research, 65(2), 142-150. https://doi.org/10.1097/nnr.00000000 00000135

Baker, G. R., \& Denis, J.-L. (2011, September). A comparative study of three transformative healthcare systems: Lessons for Canada. Canadian Health Services Research Foundation. https://www.cfhi-fcass.ca/sfdocs/default-source/commissionedresearch-reports/Baker-DenisEN.pdf?sfvrsn=0

Barnert, E. S., Coller, R. J., Nelson, B. B., Thompson, L. R., Tran, J., Chan, V., Padilla, C., Klitzner, T. S., Szilagyi, M., \&
Chung, P. J. (2019). Key population outcomes for children with medical complexity: A systemic review. Maternal and Child Health Journal, 23(9), 1167-1176. https://doi.org/10.1007/s10995-01902752-1

Boudreau, A. A., Goodman, E., Kurowski, D., Perrin, J. M., Cooley, W. C., \& Kuhlthau, K. (2014). Care coordination and unmet specialty care among children with special health care needs. Pediatrics, 133(6), 1046-1053. https://doi.org/10.1542/peds.20132174

Brault, I., Kilpatrick, K., D’Amour, D., Contandriopoulos, D., Chouinard, V., Dubois, C.-A., Perroux, M, \& Beaulieu, M.-D. (2014). Role clarification processes for better integration of nurse practitioners into primary healthcare teams: A multiple-case study. Nursing Research and Practice, 2014, Article 170514. https://doi.org/10.1155/2014/170514

Braun,V., \& Clarke,V. (2006). Using thematic analysis in psychology. Qualitative Research in Psychology, 3(2), 77-101. https://psycnet.apa.org/doi/10.1191/1 478088706qp063oa

Brehaut, J. C., \& Kohen, D. E. (2016). Complexity as a continuum of many health-related challenges. Developmental Medicine and Child Neurology, 58(11), 1099. https://doi.org/10.1111/dmcn.13238

Brenner, M., Kidston, C., Hilliard, C., Coyne, I., Eustace-Cook, J., Doyle, C., Begley, T., \& Barrett, M. J. (2018). Children's complex care needs: A systematic concept analysis of multidisciplinary language. European Journal of Pediatrics, 177(11), 1641-1652.

https://doi.org/10.1007/s00431-0183216-9

Brenner, M., O’Shea, M., Larkin, P. J., Kamionka, S. L., Berry, J., Hiscock, H., Rigby, M., \& Blair, M. (2017). Exploring integration of care for children living with complex care needs across the European Union 
and European economic area. International Journal of Integrated Care, 17(2), Article 1.

http://doi.org/10.5334/ijic.2544

Canadian Interprofessional Health

Collaborative (2010, February). $A$

National Interprofessional Competency

Framework. http://ipcontherun.ca/wpcontent/uploads/2014/06/National-

Framework.pdf

Carter, B., Cummings, J., \& Cooper, L. (2007). An exploration of best practice in multiagency working and the experiences of families of children with complex health needs. What works well and what needs to be done to improve practice for the future? Journal of Clinical Nursing, 16(3), 527-539.

https://doi.org/10.1111/j.13652702.2006.01554.x

Charlton, P., Azar, R., Luke, A., Doucet, S., Montelpare, W., Nagel, D., Hyndman, N., \& Thompson, K. (2017). Falling through the cracks: Barriers to accessing services for children with complex health conditions and their families in New Brunswick. Journal of New Brunswick Studies, 8, 133-158. https://journals.lib.unb.ca/index.php/J NBS/article/view/25883

Cohen, E., Berry, J. G., Sanders, L., Schor, E. L., \& Wise, P. H. (2018). Status complexicus? The emergence of pediatric complex care. Pediatrics, 141(S3), S202-S211. https://doi.org/10.1542/peds.2017$1284 \mathrm{E}$

Cohen, E., Dennis, Z. K., Agrawal, R., Berry, J. G., Bhagat, S. K. M., Simon, T. D., \& Srivastava, R. (2011). Children with medical complexity: An emerging population for clinical and research initiatives. Pediatrics, 127(3), 529-538. https://doi.org/10.1542/peds.20100910

D'Amour, D., Ferrada-Videla, M., San Martin Rodriguez, L., \& Beaulieu, M.-D. (2005). The conceptual basis for interprofessional collaboration: Core concepts and theoretical frameworks.
Journal of Interprofessional Care, 19(S1), 116-131.

https://doi.org/10.1080/13561820500 082529

Doucet, S., Nagel, D. A., Azar, R., Montelpare, W. J., Charlton, P., Hyndman, N., Luke, A., \& Stoddard, R. (2017). A mixed-methods Quick Strike research protocol to learn about children with complex health conditions and their families.

International Journal of Qualitative Methods, 16(1). https://doi.org/10.1177\%2F16094069 17731426

Looman, W. S., Park, Y. S., Gallagher, T. T., \& Weinfurter, E. V. (2020). Outcomes research on children with medical complexity: A scoping review of gaps and opportunities. Child: Care, Health and Development, 46(1), 121-131. https://doi.org/10.1111/cch.12725

McPherson, M., Arango, P., Fox, H., Lauver, C., McManus, M., Newacheck, P. W., Perrin, J. M., Shonkoff, J. P., \& Strickland, B. (1998). A new definition of children with special health care needs. Pediatrics, 102(1), 137-140. https://doi.org/10.1542/peds.102.1.13 7

Nelson, S., Turnbull, J., Bainbridge L., Caulfield, T., Hudon, G., Kendel, D., Mowat, D., Nasmith, L., Postl, B., Shamian, J., \& Sketris, I. (2014). Optimizing scopes of practice: New models for a new health care system. Canadian Academy of Health Sciences. https://cahsacss.ca/wpcontent/uploads/2015/07/OptimizingScopes-of-Practice_REPORT-English.pdf

Nuyen, B. A., Domogauer, J. D., Jennings, L., Kinzel, J., \& Eliason, M. J. (2019). Interdisciplinary approach to care. In J. R. Lehman, K. Diaz, H. Ng, E. M. Petty, M. Thatikunta, \& K. Eckstrand (Eds.), The equal curriculum: The student and educator guide to LGBTQ health (pp. 5770). Springer. https://doi.org/10.1007/978-3-03024025-7 
Nzirawa, T. (2015). Caring for children with complex needs. Nursing Management, 22(5), 32-38.

https://doi.org/10.7748/nm.22.5.32.e1 390

Pluye, P., Bessière, G., Bigras, M., Boulet, A., Brenner, K., Crist, E., Duong, S., Goulet, S., Granikov, V., Jean-Marie, M., Kayal, D., Kremer, B., Loignon, C., Martello, C., McLauchlin, L. R., Nguyen, Q., Omon, E., Rosenberg, E., \& Grad, R. (2014). Characteristics of complex care needs and interventions suited for patients with such needs: a participatory scoping review [Poster presentation]. North American Primary Care Research Group (NAPCRG) Annual Conference, New York, United States. https://www.mcgill.ca/familymed/files /familymed/fmfnapcrg_scopingposter_ print.pdf

Samwell, B. (2012). From hospital to home: Journey of a child with complex care needs. Nursing Children and Young People, 24(9),14-19. https://doi.org/10.7748/ncyp2012.11. 24.9.14.c9389

Shimmura, K., \& Tadaka, E. (2018). Development of an interprofessional collaboration competency scale for children with medical complexity. BMJ Open, 8(6), Article e019415. https://doi.org/10.1136/bmjopen2017-019415

Statistics Canada (2008). Participation and activity limitation survey 2006: Families of children with disabilities in Canada. https://www150.statcan.gc.ca/n1/pub /89-628-x/89-628-x2008009-eng.htm

Stewart, M. A. (2018). Stuck in the middle: the impact of collaborative interprofessional communication on patient expectations. Shoulder \& Elbow, 10(1), 66-72.

https://doi.org/10.1177/17585732177 35325

UNICEF. (2013, May). The state of the world's children 2013: Children with disabilities. https://www.unicef.org/media/84886/ file/SOWC-2013.pdf

Vos, J. F. J., Boonstra, A., Kooistra, A., Seelen, M., \& van Offenbeek, M. (2020). The influence of electronic health record use on collaboration among medical specialties. BMC Health Services Research, 20, Article 676. https://doi.org/10.1186/s12913-02005542-6

Wani, D., \& Malhotra, M. (2018). Does the meaningful use of electronic health records improve patient outcomes? Journal of Operations Management, 60(1), 1-18. https://doi.org/10.1016/j.jom.2018.06. 003

Ward, C., Glass, N., \& Ford, R. (2015) Care in the home for seriously ill children with complex needs: A narrative literature review. Journal of Child Health Care, 19(4), 524-531. https://doi.org/10.1177/13674935145 38327

World Health Organization. (2011, December 14). World report on disability. https://www.who.int/publications/i/it em/world-report-on-disability

Zwarenstein, M., \& Reeves, S. (2006). Knowledge translation and interprofessional collaboration: Where the rubber of evidence-based care hits the road of teamwork. The Journal of Continuing Education in the Health Professions, 26(1), 46-54. https://doi.org/10.1002/chp.50 